\title{
Determination of processing windows for the hot stamping of AA7075
} Qunli Zhang ${ }^{a}$, Kang Ji ${ }^{b}$, Omer El Fakir ${ }^{c}$, Xiaochuan Liu ${ }^{d}$ and Liliang Wang ${ }^{*}$

\author{
Department of Mechanical Engineering, Imperial College London, London, SW7 2AZ, UK \\ aqunli.zhang14@imperial.ac.uk, bk.ji13@imperial.ac.uk, comar.al-fakir07@imperial.ac.uk, \\ dxiaochuan.liu14@imperial.ac.uk, eliliang.wang@imperial.ac.uk
}

Keywords: Hot stamping, AA7075, processing windows, Tailor

\begin{abstract}
Hot stamping of aluminium alloys is a tailored forming process, with the assigned processing windows determining the quality of each hot stamped component in terms of its post-form strength. In this work, a processing window calculator, 'Tailor', was developed in order to define the optimal processing parameters that should be used in a production line to successfully produce a component with the desired post-form strength using hot stamping. 'Tailor' was developed using the results of forming tests, air-cooling tests and multi-stage artificial ageing tests, which provided guidance on the values for the die closing force, transfer time and artificial ageing time to be used in the hot stamping process. The effectiveness of 'Tailor' was demonstrated in two case studies.
\end{abstract}

\section{Introduction}

Growing concerns about environmental problems caused by greenhouse gas emissions have stimulated the automotive industry to improve vehicle efficiencies [1]. According to work by Lutsey, if the steel components in a car body structure are replaced by lightweight alloys such as aluminum alloys, the weight of the vehicle can be reduced by over $40 \%$, and correspondingly, the efficiency of the vehicle would be improved by over 30\% [2-4]. The demand for high strength aluminium alloys is therefore increasing, in the automotive industry as well as the aerospace and locomotive industries [5].

Due to their limited formability at room temperature, traditional forming technologies are not applicable for the forming of complex-shape components from aluminium alloys [6]. Hot stamping is one of the advanced technologies developed to overcome some of these challenges, and is a hybrid forming process that combines metal forming and heat treatment in a single operation [7]. The viscoplastic behavior of the workpiece material at elevated temperatures affects the material flow and hence the quality of the formed component [8]. Concurrently the workpiece temperature evolution before, during, and after hot stamping, influences the microstructure of the material and thus the postform strength. Determining the optimal forming parameters in a hot stamping process to achieve a component with the desired strength is therefore essential.

A typical hot stamping process involves solution heat treating (SHT) of the workpiece material to dissolve the precipitates into the Al matrix, usually in a convection heater or furnace. During SHT, the workpiece material is soaked at the desired temperature for a certain period of time to ensure that all the precipitates are fully dissolved. Longer periods of soaking are usually beneficial for the formability of the material, as they ensure that the precipitates are fully dissolved. However, for some high strength aluminum alloys, overheating could lead to premature fracture [9]. The workpiece is then transferred to a press and formed at a high speed to avoid excessive heat loss and retain a sufficient viscoplastic response and formability in the workpiece. A high forming speed would also enhance the strain and strain rate hardening responses of the workpiece material, which influences the onset of localized necking [7,10]. Quenching (fast cooling) by water cooled dies will 'freeze' the workpiece material during and after forming to obtain a microstructure in a desirable super saturated solid solution (SSSS) state [11]. A quenching rate above the critical quenching rate of the workpiece material is essential to avoid the generation of coarse precipitates on the grain boundaries, which diminishes the artificial ageing response of the workpiece material $[12,13]$. Fast quenching is realized 
by the die closing force which influences the value of interfacial heat transfer coefficient (IHTC) [14]. Therefore, a sufficient die closing force is required during the quenching stage.

Artificial ageing follows the forming process, and can retain the full mechanical strength of the material through the development of finely distributed precipitates [11]. It is essential that the time and temperature used in the artificial ageing process is set such that dispersed precipitates with a suitable size and inter-particle distance can be obtained. Ideally, natural ageing should be avoided such that its detrimental effects on the material's response to artificial ageing can be reduced. Conventional artificial ageing processes take up to 48 hours for some aluminium alloy, e.g. AA7075. Applying intermediate artificial ageing followed by paint bake and (or) curing thermal cycles would significantly reduce the time required for artificial aging, from 48 hours to less than 2 hours, which could save energy significantly and enhance productivity [15-17].

Previously, the determination of the optimal processing window for a forming process had not been conducted using a combination of the different inter-related parameters in a single model. In this paper, Experiments including forming tests and heat treatment tests were performed to derive the influences of different processing parameters, and the results combined to provide a comprehensive multi-disciplinary software code of the hot stamping process. Namely, a knowledge based software code - 'Tailor', was developed to determine processing parameters effectively and reliably.

\section{Experimental procedure}

Forming tests. A hot stamping simulator was designed to simulate stamping processes for aluminium alloys, shown in Fig.1, and assembled in a thermo-mechanical simulator, the Gleeble 3800. Test specimens were cut from AA7075 sheet with $2 \mathrm{~mm}$ thickness. To reproduce the hot stamping process for AA7075, the dog-bone shaped workpiece was pre-heated to $490^{\circ} \mathrm{C}$ for solution heat treatment and soaked for a certain period of time that ensured a homogeneous temperature distribution and a full dissolution of the precipitates in the aluminium matrix. The workpiece was then compressed and quenched by the cylindrical cold dies under a defined contact pressure (from 0 to $20 \mathrm{MPa}$ ) and under different lubricant conditions. The temperature evolution was recorded and used to analyze the effect of the die closing force and lubricant condition on the interfacial heat transfer coefficient (IHTC).

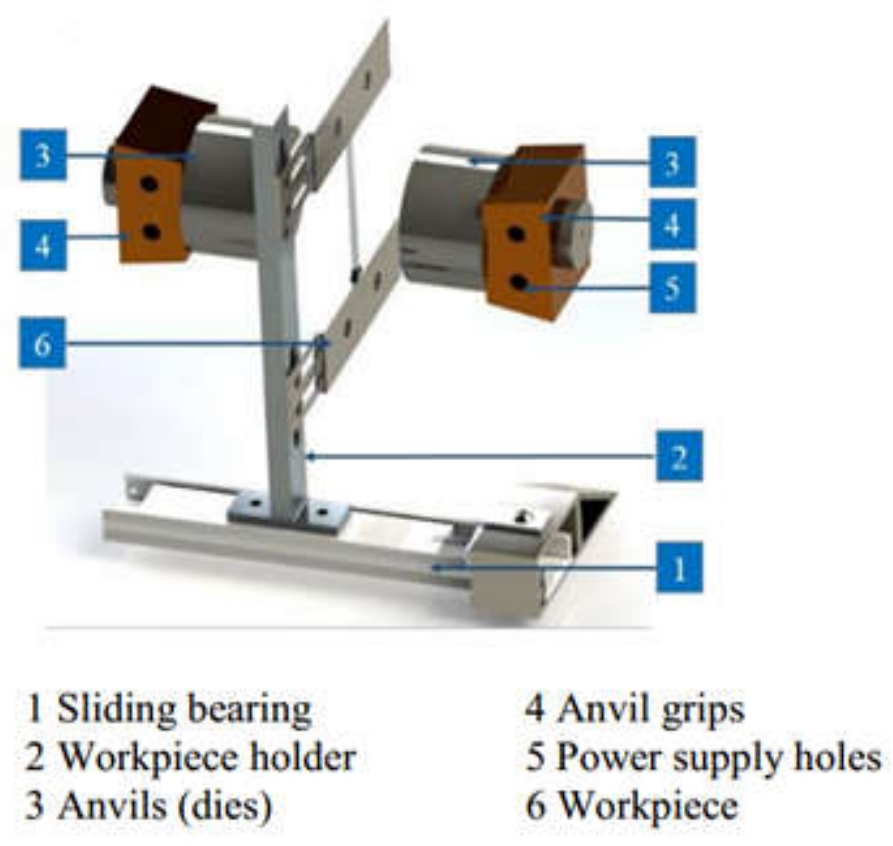

Fig. 1: Hot stamping simulator [14]

Air-cooling tests. Air-cooling tests were carried out to investigate the effect of the geometry of the specimen on the ideal transfer time from the furnace to the press after solution heat treatment. The samples were cut from $2 \mathrm{~mm}$ thick AA7075 blanks with the following dimensions: $20 \times 20 \mathrm{~mm}, 20 \times 45$ 
$\mathrm{mm}, 22.5 \times 40 \mathrm{~mm}, 30 \times 30 \mathrm{~mm}$ and $40 \times 40 \mathrm{~mm}$. The size parameters for these specimens are shown in Table 1.

Table 1: Size parameters of the test specimens

\begin{tabular}{cccccc}
\hline Length [mm] & Width $[\mathrm{mm}]$ & Thickness $[\mathrm{mm}]$ & Area $\left[\mathrm{mm}^{2}\right]$ & Volume $\left[\mathrm{mm}^{3}\right]$ & A/V ratio \\
\hline 20 & 20 & 2 & 960 & 800 & 1.2000 \\
20 & 45 & 2 & 2060 & 1800 & 1.1444 \\
22.5 & 40 & 2 & 2050 & 1800 & 1.1389 \\
30 & 40 & 2 & 2040 & 1800 & 1.1333 \\
40 & 40 & 2 & 3520 & 3200 & 1.1000 \\
\hline
\end{tabular}

Two K-type thermos-couples were attached to the samples, one at their center and the other at their corner, to monitor and record their temperature history using a data logger.

Heat treatment tests. Workpieces with dimensions of $20 \times 20 \mathrm{~mm}$ were cut from the $2 \mathrm{~mm}$ thick AA7075 blanks for the artificial ageing tests, conducted using chamber furnaces. Two methods were adopted: one-step artificial ageing (AA) and two-step artificial ageing. In the one-step AA tests, the workpiece was heated to $121^{\circ} \mathrm{C}$ and soaked for 48 hours. In the two-step AA tests, the material was held at $121^{\circ} \mathrm{C}$ for $4,25,55,120$ and 240 minutes in the first step, followed by a second-stage ageing at $177^{\circ} \mathrm{C}$ for $0-120$ minutes (as occurs in the paint bake cycles). The resulting specimen hardness was recorded for each condition and extracted to verify and develop the model for the artificial ageing response.

\section{Results and Discussion}

Determination of die closing force. It was found that the IHTC increases with increased contact pressure (die closing force/contact areas) and remained stable at 12.3 and $20.4 \mathrm{~kW} /\left(\mathrm{m}^{2} \mathrm{~K}\right)$ under the dry condition and lubricated condition as shown in Fig. 2. The IHTC is an important parameter which ensures that the attained quenching rate is higher than the critical quenching rate. The detailed experimental results and models can be found in [14]. Criticial die closing force is determined accordingly to ensure that critical quenching rate is attained during the quencing stage, which is component size and geometry dependent.

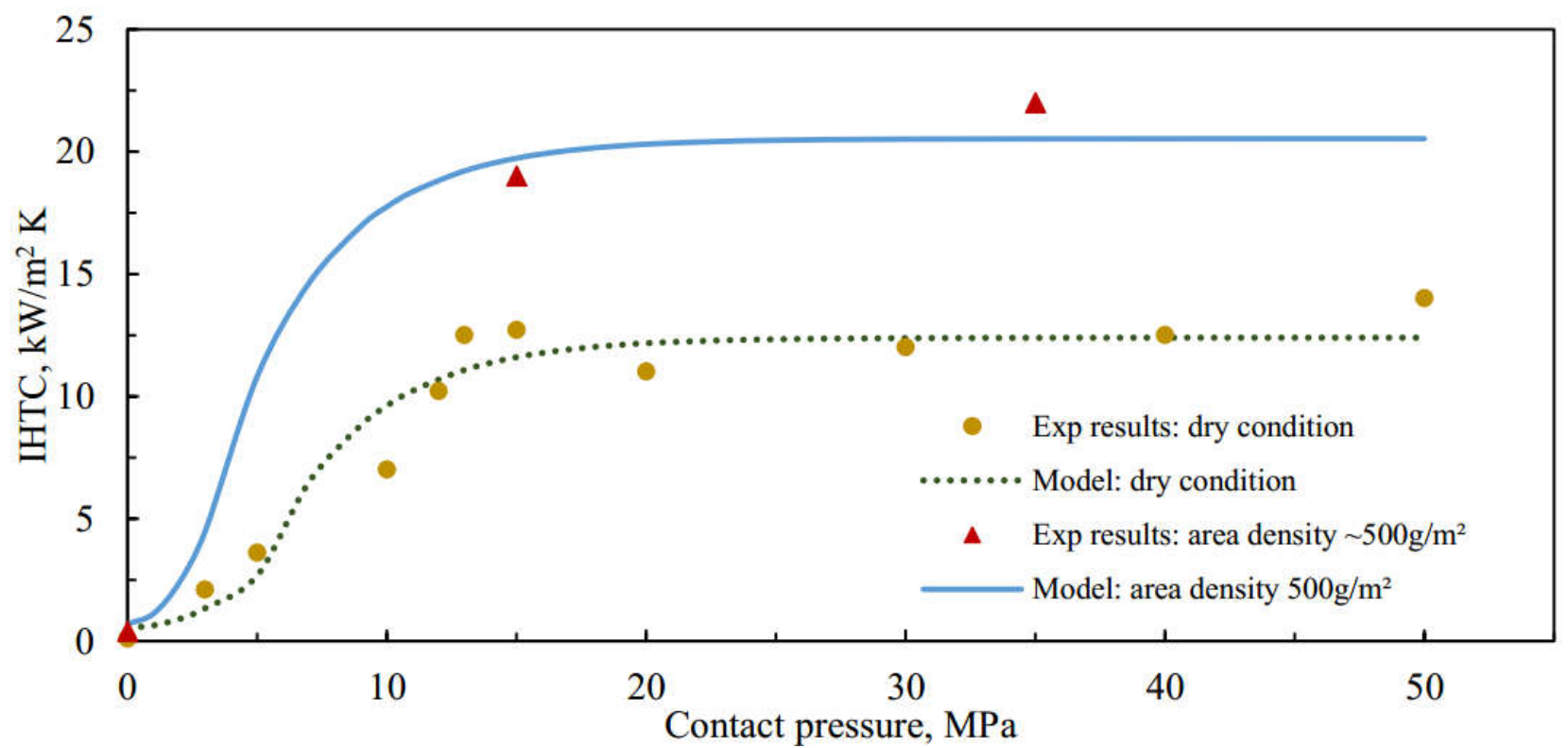

Fig. 2: Effects of contact pressure on the IHTC [14] 
Determination of transfer time. Comparisons of the temperature evolutions for different specimens during hot blank transfer is shown in Fig. 3 which illustrates that a larger area to volume ratio leads to a higher cooling rate.

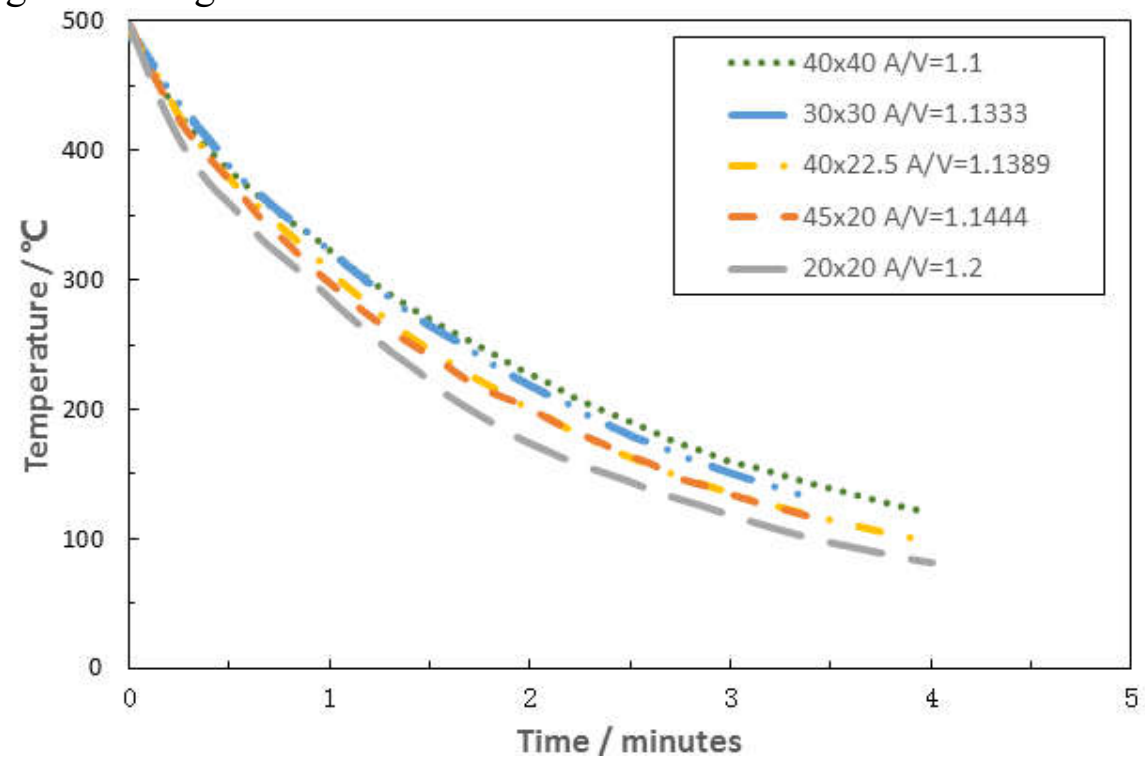

Fig. 3: Temperature evolution of the different specimens

Accurate control of transfer time from the furnace to the press is crucial for keeping the workpiece temperature high enough to maintain sufficient formability. Theories of heat transfer were applied to establish a model to predict the real-time temperature of components during transfer from the furnace to the forming press, for implementation in the processing windows calculator. The model comprises two terms: the first one is a heat convective coefficient model, and the second one is a real-time temperature calculation model.

Normally, the blanks are flat sheets, of which the internal temperature distribution is assumed homogeneous. Two widely used methods, the Reynolds analogy and modified Reynolds analogy, also known as Chilton-Colburn analogy, were applied to establish the heat convective coefficient model $[18,19]$. Three equations of dimensionless numbers were first defined to describe the character of the heat transfer system:

$$
\begin{aligned}
\mathrm{Nu} & =\frac{h l}{\lambda} \\
\mathrm{Nu} & =0.664 \operatorname{Re}^{1 / 2} \operatorname{Pr}^{1 / 3} \cdot \frac{\lambda}{l} \\
\mathrm{Re} & =\frac{v l}{v}
\end{aligned}
$$

Where $N u$ is the Nusselt number, Re is the Reynolds number, $\operatorname{Pr}$ is the Prandtl number, $h$ is the heat convective coefficient, $l$ is the characteristic length of the system, $\lambda$ is the thermal conductivity of the specimen, $v$ is the velocity of the flow and $v$ is the kinematic viscosity [20-22].

Rearranging the equations, a new equation for $h$ was derived:

$$
h=0.664 \operatorname{Re}^{1 / 2} \operatorname{Pr}^{1 / 3} \cdot \frac{\lambda}{l}=0.664\left(\frac{v l}{v}\right)^{1 / 2} \operatorname{Pr}^{1 / 3} \cdot \frac{\lambda}{l}
$$

Referring to the tables for the physical properties of air, the Prandtl number and kinematic viscosity were found with the characteristic temperature of the system [20]. The heat convective coefficient $h$ could then be acquired with all the known parameters.

The lumped parameter method was used to simulate the relationship between the temperature of the components and the transfer time in air, which is a simplified method used to neglect the nonuniformity of the components. The Biot number $B i$ is calculated first to determine whether this method is valid. The Biot number is the ratio of the heat transfer resistances inside of and at the surface of a body, and describes the temperature distribution of the specimen [23]. Generally, the temperature of the specimen can be assumed to be uniform if the $B i$ number is less than 0.1 . 
Excess temperature is defined as:

$\theta=T-T_{\infty}$

Where $T$ and $T_{\infty}$ denote the temperature of the specimen and the surrounding temperature. According to Newton's law of cooling:

$$
\rho c V \frac{d \theta}{d t}=-h A \theta
$$

Where $\rho$ is the density of the specimen, $c$ the specific heat capacity of the specimen, $t$ the cooling time, $A$ the surface area of the specimen and $V$ the volume of the specimen.

Rearranging and integrating the equation, the transient temperature of the specimen could be described:

$$
T=T_{\infty}+\left(T_{0}-T_{\infty}\right) \exp \left(-\frac{h A}{\rho c V} t\right)
$$

The equation also confirms that the cooling rate is dependent on the area to volume ratio. The exponential term decreases quicker with a larger area to volume ratio, which accounts for the faster cooling rate. During the transfer process, the transfer time is known, and hence the temperature could be computed from the equation. The optimal transfer time could also be calculated inversely according to the desired target temperature.

Table 2: Material properties of the test specimens

\begin{tabular}{ccc}
\hline$\lambda[\mathrm{W} /(\mathrm{m} \cdot \mathrm{K})]$ & $\rho[\mathrm{kg} / \mathrm{m} 3]$ & $c[\mathrm{~J} / \mathrm{kg} \cdot \mathrm{K}]$ \\
\hline 130 & 2810 & 960 \\
\hline
\end{tabular}

The air-cooling model was verified by comparing the numerical results with the experimental results. The temperature difference between the central and corner regions of the specimen were negligible, which meant that the temperature distribution could be considered uniform. Therefore, only the central temperature evolution was plotted so as to simplify the comparison. As can be seen in Fig. 4, for the $40 \times 40 \mathrm{~mm}$ specimen, the predicted temperature evolution was accurate, showing good agreement with the experimental results, with error less than $2.5 \%$.

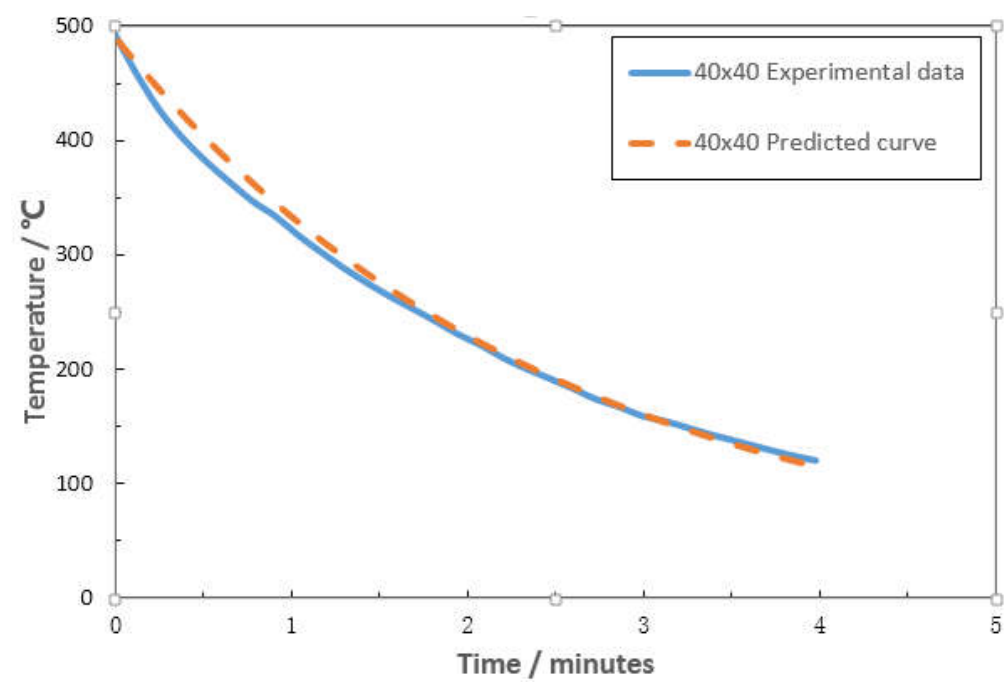

Fig. 4: Comparison between experimental and predicted temperature evolution

Determination of processing parameters for artificial ageing. Fig. 5 presents the hardness evolution for the artificial ageing of AA7075 with different ageing times. The effect of thermal history is significant for AA7075 as the peak hardness attained in addition to the time taken to reach the peak hardness are affected. As can be seen, for one-step ageing, the hardness increases with ageing time, reaches the peak value at about 48 hours and then drops at longer period of ageing time. Additionally, after second-step ageing, the peak hardness increases first with increasing pre-ageing time, and then 
decreases when pre-ageing time is longer than 2 hours. Furthermore, the second-step ageing time required to achieve the peak hardness increases with increasing pre-ageing time. More specifically, 4, 120 and 240 minutes first-step ageing requires 55, 60 and 70 minutes second-step ageing, respectively.

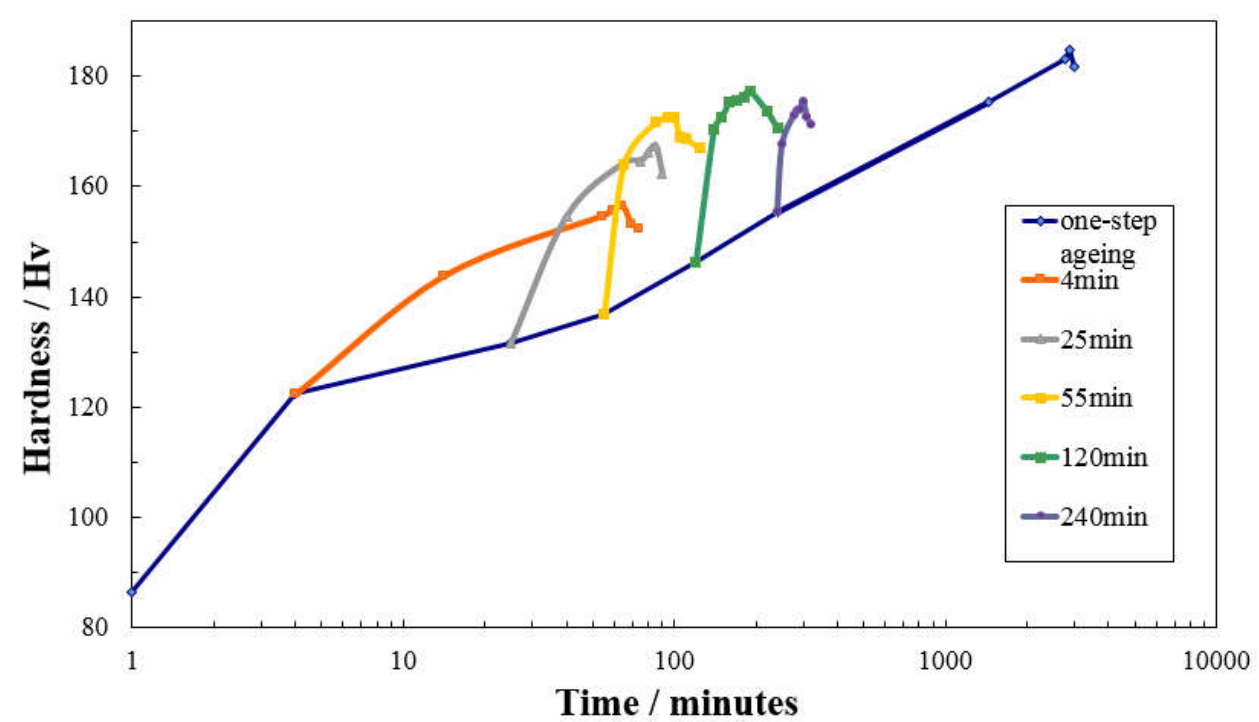

Fig. 5: Effect of thermal history on hardness

During the artificial ageing process, the hardening mechanism involves the formation of GP zones and metastable $\eta$ ' precipitates, which restrict dislocation motion and hence strengthen the material. $\eta$ ' precipitates are regarded as being responsible for the peak hardening of AA7075 [11,24].

For one-step ageing, the hardness increases to a peak value from 0 to 48 hours due to the formation of $\eta$ ' precipitates and starts to decrease after 48 hours because the $\eta$ ' precipitates begin to transform to $\eta$ precipitates. For two-step ageing, it has been suggested that, during first-step ageing at $121^{\circ} \mathrm{C}$, the radius of the GP zones grow and their volume fraction increases, which enables the GP zones to transform into the metastable $\eta$ ' phase precipitates [11]. The conversion from GP zones to $\eta$ ' precipitates is accelerated in the second-step ageing at $177^{\circ} \mathrm{C}$, which enhances the material to its peak strength. Theoretically, the peak strength increases at first with increasing pre-ageing time and then decreases when the time is too long due to the change in the type of early stage precipitates, which would affect the size and distribution of precipitates in the second-step ageing. It is essential to assign the second-step ageing time appropriately as well; too short a period of time cannot ensure that the $\eta$ ' precipitates are fully transformed, while too long a period of time would convert the $\eta$ ' precipitates to more stable state $\eta$ precipitates, which would reduce the strength of the material (overageing) $[11,25,26]$.

Processing windows calculator - 'Tailor'. Hot stamping of aluminium alloy is a tailored forming process. Namely, a unique processing window should be characterized and defined for each hot stamped component, due to the fact that downstream operations would significantly affact the postform strength of aluminium pressings. Two main targets were considered in developing the processing windows calculator; the first was to define tailored forming parameters or processing windows, according to the capacity of existing facilities in a press shop, accurately and effectively in the production line. The second was to customize the processing windows for different stamped components. With correctly determined and controlled processing windows, the desired quality of the formed components would be achieved with consistent results, at the highest possible production rate and lowest possible cost. Instead of using separate programs to calculate different processing windows at each step, integrating multi-disciplinary theories into one software package would minimize the workload and probability of error, enabling a series of inter-related parameters to be 
computed efficiently. The developed software 'Tailor' provides visualized control panels and customized parameter selections for users, as well as a set of accurate processing window outputs.

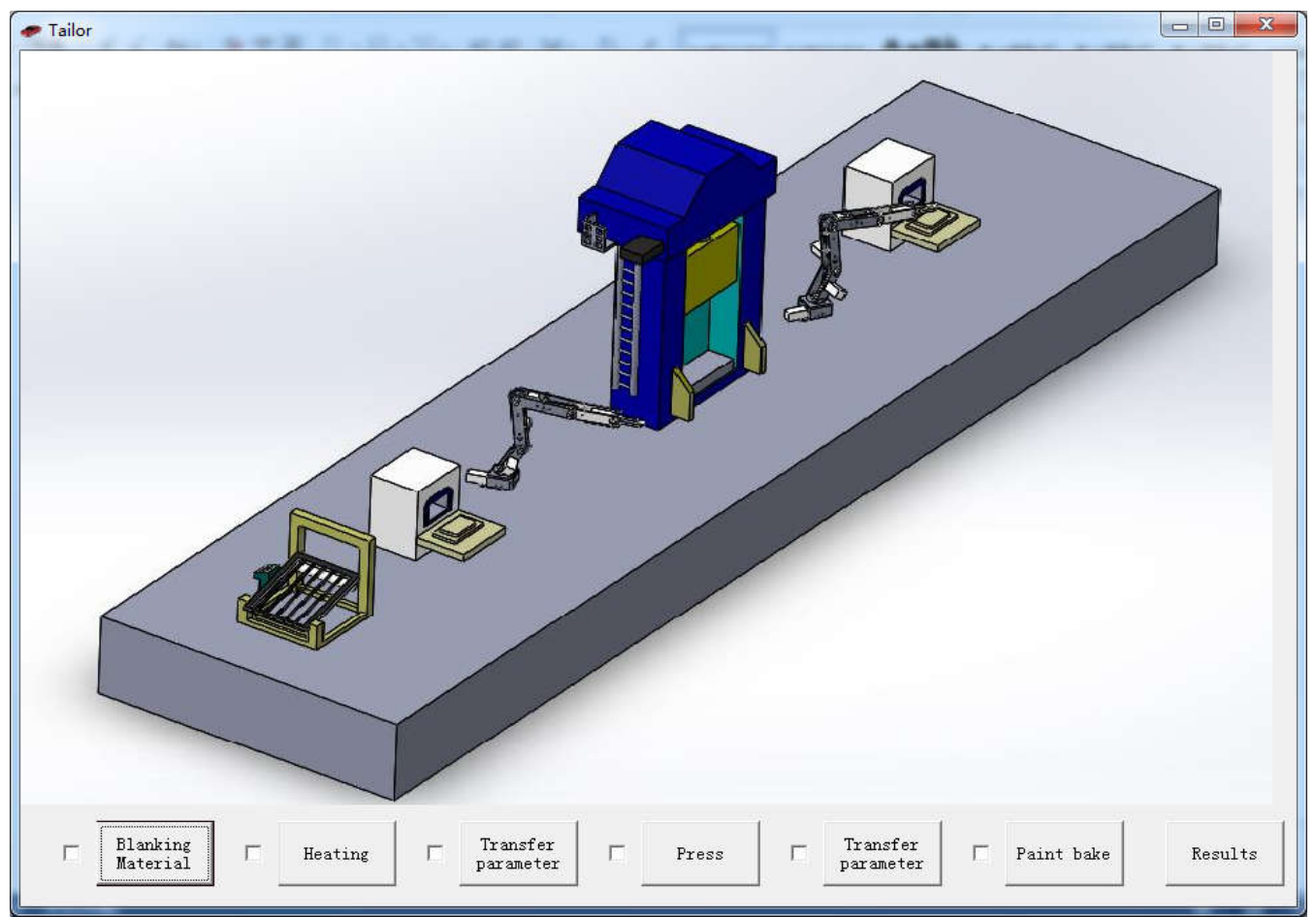

Fig. 6: Parameter definition control panel in Tailor

Fig. 6 demonstrates the parameter definition control panel of 'Tailor', where the picture illustrates the production line for the hot stamping of an aluminium alloy. The parameters to be defined in Tailor come from six major modules of a production line for hot stamping: blanking, heating, hot blank transfer, hot stamping, formed component transfer, paint bake, and optimized processing window outputs. Fig. 7 demonstrates the parameter definitions for the paint bake cycle.

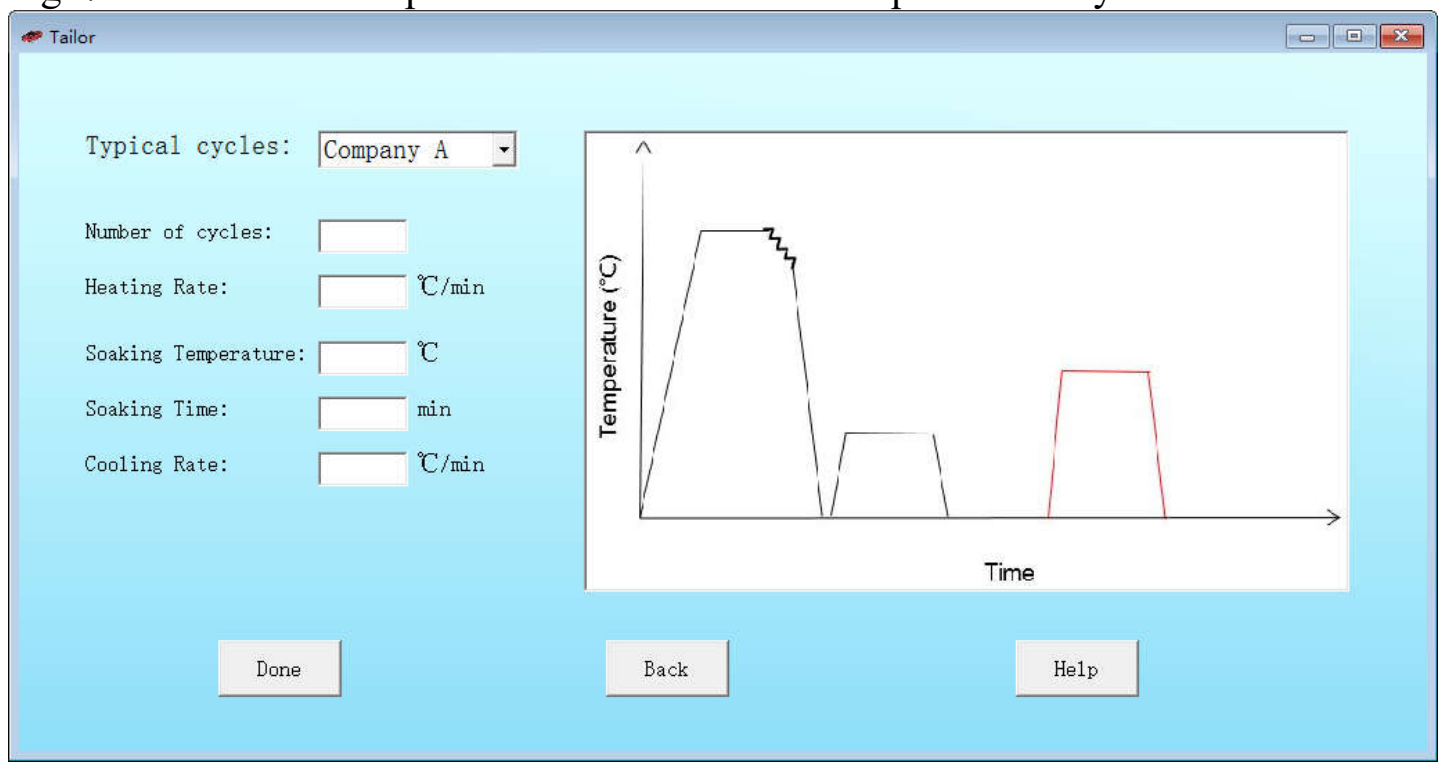

Fig. 7: Pant bake cycle control panel

Fig. 8 illustrates the results panel, where the optimized processing windows computed by 'Tailor' for producing a high strength component are shown. 'Tailor' displays all the optimal processing windows including: the SHT temperature, SHT soaking time, transfer time, die closing force and preageing time. These windows are computed according to the developed models for the IHTC, air cooling and artificial ageing, and the data input by the user. 


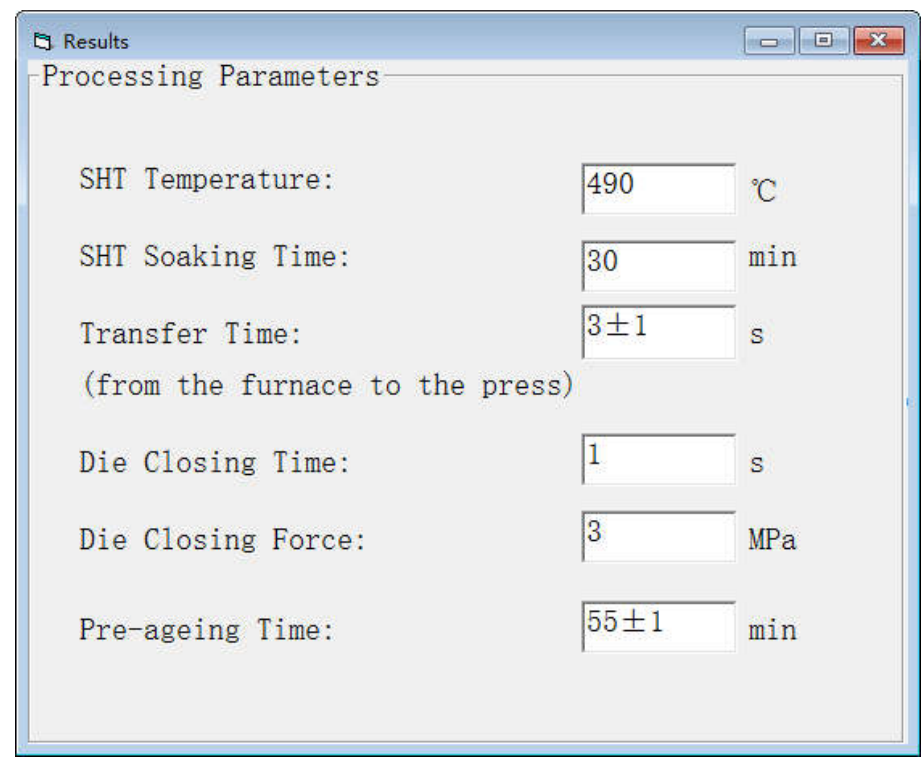

Fig. 8: Processing window predicted by 'Tailor' based on existing facilities for production

Two case studies were performed to demonstrate the effectiveness of 'Tailor'. In the first case, processing windows were predicted by 'Tailor' for a component produced by two different companies, while in the second case, processing windows for components assembled in different locations were predicted. As represented in Table 3, for the same component, when the paint bake cycle time is 40 minutes in Company A and 60 minutes in Company B, pre-ageing for 55 minutes and 74 minutes would be required to ensure the final strength of the material.

Table 3: Results for Case 1, a component produced by two different companies.

\begin{tabular}{ccc}
\hline & Company A & Company B \\
\hline Area-volume ratio & 2.07 & 2.07 \\
Transfer time [s] & $10 \pm 2$ & $10 \pm 2$ \\
from furnace to press & $\mathbf{5 5 \pm 1}$ & $\mathbf{7 4 \pm 1}$ \\
Artificial ageing time [minutes] & 121 & 121 \\
Artificial ageing temperature $\left[{ }^{\circ} \mathrm{C}\right]$ & $\mathbf{4 0}$ & $\mathbf{6 0}$ \\
Paint bake cycle time [minutes] & 177 & 177 \\
Paint bake cycle temperature $\left[{ }^{\circ} \mathrm{C}\right]$ & $\mathbf{1 7 4 . 5}$ & $\mathbf{1 7 4}$ \\
Post-form hardness [Hv] & & \\
\hline
\end{tabular}

Table 4 shows that the required transfer time for Component $\mathrm{A}$ is $33.7 \%$ shorter than that of Component B due to the increased area to volume ratio (from 1.41 to 2.07). A larger area to volume ratio leads to a larger heat transfer surface area, resulting in more heat loss, hence faster cooling rate. The temperature reduction of the blank material should be minimized to maintain sufficient formability, hence the transfer speed must be higher.

Table 4: Results for Case 2

\begin{tabular}{ccc}
\hline & Component A & Component B \\
\hline Area-volume ratio & 2.07 & 1.41 \\
Transfer time [s] & $\mathbf{1 0 \pm 2}$ & $\mathbf{1 5 . 0} \pm \mathbf{2}$ \\
from furnace to press & $55 \pm 1$ & $74 \pm 1$ \\
Artificial ageing time [minutes] & 121 & 121 \\
Artificial ageing temperature $\left[{ }^{\circ} \mathrm{C}\right]$ & 40 & 40 \\
Paint bake cycle time [minutes] & 177 & 177 \\
Paint bake cycle temperature $\left[{ }^{\circ} \mathrm{C}\right]$ & 174.5 & 174.5 \\
Post-form hardness [Hv] & & \\
\hline
\end{tabular}




\section{Conclusion}

Experiments were performed to reproduce the entire hot stamping process for AA7075, through forming tests, air-cooling tests and multi-stage artificial ageing tests. The effects of different processing windows on the quality of the formed components were also studied in terms of the postform strength.

It was found that IHTC increased with contact pressure and remained stable at 12.3 and $20.4 \mathrm{~kW} /$ $\left(\mathrm{m}^{2} \mathrm{~K}\right)$ under the dry condition and lubricated condition. Criticial die closing force is determined accordingly to achieve a quenching rate above the critical quenching rate, such that a super saturated solid solution microstructure could be attained. Additionally, the transfer time from the furnace to the press should be controlled accurately within a proper range in order to maintain the formability of the workpiece at an elevated temperature; a model was developed such that the temperature evolution of the workpiece could be determined. A faster ageing process for AA7075 was also proposed, and it was deduced that in the first step of this process that the ageing time should be lower than 2 hours to achieve a sufficiently high post-form strength and avoid the formation of coarse precipitates.

The models derived from the tests and physical theories were coded into 'Tailor', a processing windows calculator. The dedicated software 'Tailor' provides visualized operation interfaces for the setup of parameters and offers accurate determination of processing windows, of which the effectiveness has been demonstrated by comparing the results of two case studies.

\section{References}

[1] H. Hao, Z. Liu, F. Zhao, W. Li, and W. Huang, Scenario analysis of energy consumption and greenhouse gas emissions from China's passenger vehicles, Energy, 91(2015) 151-159.

[2] O. Fakir, L. Wang, D. Balint, J. Dear, and J. Lin, Numerical study of the solution heat treatment, forming and in-die quenching (HFQ) price on AA 5754, Int. J. of Mach. Tool Manu., 87 (2014) 3948.

[3] Davis, Review of technical literature and trends related to automobile mass-reduction technology, Institute of Transportation Studies, University of California, Davis, 2010.

[4] W.S. Miller, L. Zhuang, J. Bottema, A. Wittebrood, P. De Smet, A. Haszler, A. Vieregge, Recent development in aluminium alloys for the automotive industry, Mater. Sci. Eng. A Struct. Mater. Prop. Microstruct. Process., 280 (2000) 37- 49.

[5] P. Lequeu, P. Lassince, T. Warner and G.M. Raynaud, Engineering for the future: weight saving and cost reduction initiatives, Aircr Eng. Aerosp. Tec., 73 (2001) 147-159.

[6] I.J. Polmear, Light Alloys: Metall. Light Met., third ed., Wiley Press, New York, 1995.

[7] M. Mohamed, J. Foster and J. Lin, Solution heat treatment in HFQ process, Steel Res. Int., 11 (2008) 160-167.

[8] M.F. Novella, A. Ghiotti, S. Bruschi, P.F. Bariani, Ductile damage modeling at elevated temperature applied to the cross wedge rolling of AA6082-T6 bars, J. Mater. Process. Technol., 222 (2015) 259-267.

[9] R.P. Garrett, J. Lin and T.A. Dean, An investigation of the effects of solution heat treatment on mechanical properties for AA 6xxx alloys: experimentation and modelling, Int. J. Plast., 21 (2005) 1640-1657.

[10] C.M Abreu, M.J. Cristobal, R. Figueroa and G. Pena, Wear and corrosion performance of two different tempers (T6 and T73) of AA7075 aluminium alloy after nitrogen implantation, Appl. Surf. Sci., 327 (2015) 51-61.

[11] S.V. Emani, J. Benedyk, P. Nash and D. Chen, Double aging and thermomechanical heat treatment of AA7075 aluminum alloy extrusions, J. Mater. Sci., 44 (2009) 6384-6391. 
[12] X. Fan, Z. He, S. Yuan and P.Lin, Investigation on strengthening of 6A02 aluminum alloy sheet in hot forming-quenching integrated process with warm forming-dies, Mater. Sci. Eng., 587 (2013) 221-227.

[13] M.J. Starink, N. Gao, L. Davin, J.Yan, and A. Gerezo, Room temperature precipitation in quenched $\mathrm{Al}-\mathrm{Cu}-\mathrm{Mg}$ alloys: a model for the reaction kinetics and yield strength development, Philos. Mag., 13 (2005) 1395-1417.

[14] X. Liu, K. Ji, O. Fakir, J. Liu, Q. Zhang and L. Wang, Determination of Interfacial Heat Transfer Coefficient in the Hot Stamping of AA7075. $4^{\text {th }}$ international Conference on New Forming Technology, 2015.

[15] Y. Xiao, Q. Pan, W. Li, X. Liu and Y. He, Influence of retrogression and re-aging treatment on corrosion behaviour of an Al-Zn-Mg-Cu alloy, Mater. Design, 32 (2011) 2149-2156.

[16] X. Huang, Q. Pan, B. Li, Z. Liu, Z. Huang and Z. Yin, Microstructure, mechanical properties and stress corrosion cracking of Al-Zn-Ma-Zr alloy sheet with trance amount of Sc, J. Alloys Compd., 650 (2015) 805-820.

[17] J. Lin, T.A. Dean, R.P. Garrett, A process in forming high strength and complex-shaped Al-alloy sheet components, British Patent, UK, 2008.

[18] Z. Duan, and B. He, Extended Reynolds analogy for slip and transition flow heat transfer in micro channels and nanochannels, Int. J. Heat Mass Transf., 56 (2014) 25-30.

[19] P.T. Tsilingiris, Modeling heat and mass transport phenomena at higher temperatures in solar distillation systems - The Chilton-Colburn analogy, Sol. Energy, 84 (2010) 308-317.

[20] A. Bejan, Convection Heat Transfer, fourth ed., John Wiley \& Sons, New Jersey, 2013

[21] D. Mclean, Understanding Aerodynamics: Arguing from the Real Physics, second ed., John Wiley \& Sons, Chichester, 2012.

[22] A.Myerson, Handbook of Industrial Crystallization, Butterworth-Heinemann, second ed., Oxford, 2002.

[23] J. Tu, K. Inthavong and G. Ahmadi, Computational Fluid and Particle Dynamics in the Human Respiratory System, Springer Sci. \& Business Media, 2012.

[24] S. Gang and C. Alfred, Early-stage precipitation in Al-Zn-Mg-Cu alloy, Acta Mater., 52 (2004) 4503-4516.

[25] R. Ferragut, A. Somoza, A. Tolley and I. Torriani, Precipitation kinetics in Al-Zn-Mg commercial alloys, J. Mater. Process. Technol., 41(2003) 35-40.

[26] L.K. Berg, J. Gjønnes, V. Hansen, X.Z. Li and M. Knutson-Wedel et al., GP-zones in Al-Zn$\mathrm{Mg}$ alloys and their role in artificial aging, Acta Mater., 49 (2001) 3443-3451. 